\title{
Clinical and Functional Comparison between Anatomical and Non-Anatomical Acute Repair of Tears of the Distal Tendon of Biceps Brachii
}

\author{
A. De Carli' ${ }^{1}$ E. Gaj', S. M. Pagnotta ${ }^{1}$, O. Picconi ${ }^{2}$, A. Ferretti ${ }^{1}$ \\ 1 Orthopaedic Unit and Kirk Kilgour Sports injury Center, S. Andrea Hospital, La Sapienza University of Rome, \\ Rome, Italy \\ 2 National HIV/AIDS Research Center, Istituto Superiore di Sanità, Rome, Italy
}

\section{CORRESPONDING AUTHOR:}

Edoardo Gaj

Orthopaedic Unit and Kirk Kilgour Sports

injury Center

S. Andrea Hospital

University of Rome Sapienza

via di Grottarossa 1035-1039

00189 Rome, Italy

E-mail: edoardogaj@gmail.com

DOI:

10.32098/mltj.03.2021.07

LEVEL OF EVIDENCE: 3

\begin{abstract}
SUMMARY
Aim. The aim of this study was to investigate whether the anatomical reconstruction on the radial tuberosity could be superior to the non-anatomical repair by tenodesis on brachialis, in terms of clinical outcomes and isokinetic evaluation to treat distal biceps brachii tendon ruptures.

Methods. We retrospectively evaluated 36 patients at the final follow up; 16 were treated with the anatomical technique (Group A) and 20 with the non-anatomical (Group B). The isokinetic testing was used to assess the functional performance of both arms during flexion/extension and supination/pronation. We determined the Peak Torque, Total Work and Endurance. The clinical outcomes were evaluated using the main evaluation scales (DASH, Oxford Elbow score and MEPS). The Wilcoxon Two-Sample Test and the Chi-Square were used to evaluate the differences between the two groups for quantitative variables and qualitative variables, respectively.

Results. According to clinical score, both treatments were considered satisfactory. The dynamometric tests demonstrated an overall superiority of the anatomical group compared to the non-anatomical group, with a statistical significant difference $(\mathrm{p}<$ 0.05 ) in the Peak Torque evaluated in flexion both at $90 \%$ seconds and at $210 \%$ seconds. The dominant arms achieved better results compared to the non-dominant extremities in all the tests. No major complications in any of the patients were reported.

Conclusions. The anatomical technique using transosseous tunnels is a safe and effective procedure when used in acute patients. Although the non-anatomical treatment presented satisfactory results, the anatomical treatment is able to significantly reduce all the residual functional deficits usually present after the repair.
\end{abstract}

KEY WORDS

Distal biceps tendon; rupture; elbow; isokinetic test; repair; acute treatment.

\section{INTRODUCTION}

Distal biceps brachii tendon avulsions account for only $3 \%$ of all biceps ruptures, the proximal ruptures of the long head and of the short head represent respectively $96 \%$ and $1 \%(1)$.

The ruptures of the distal tendon of the biceps brachii occur more frequently in the dominant extremity of middle-aged men (40-60 years of age) (2). The average incidence of this injury is 1.20 events per 100.000 population per year (3).
Acute injuries occur more frequently in heavy workers and weight 3 tive tendon biomechanics, restoring the native tendon moment arm and forearm rotation, compared to the non-anatomical approach (15).

The purpose of this study is to investigate whether the anatomical single-incision approach could be superior to the non-anatomical biceps tenodesis to the brachialis tendon, in terms of clinical outcomes and isokinetic tested flexion and supination strength. Our null hypothesis consists in the clin- 
ical and functional superiority of the anatomical technique compared to the non-anatomical, especially in supination.

\section{MATERIALS AND METHODS}

In this study we performed a retrospective analysis of 45 patients diagnosed with rupture of distal biceps brachii tendon, surgically treated in acute setting $(<3$ weeks $)$ at our Institution by our upper extremity expert surgeon from October 2007 to October 2017. Nine patients were not available to perform the isokinetic evaluation: 4 in the anatomical group and 5 in non-anatomical group. Among these, two patients withdrawn for health issues, one patient passed away and six were not available to perform the tests. We gathered all the information on the clinical condition of the patients, mechanism of injury, level of activity, dominant extremity and general data from our Hospital charts. Out of these 36 patients, 16 patients were treated with a single-incision anatomical approach (Group A), while 20 were treated with a non-anatomical brachialis anterior tenodesis (Group B). The mean age of the two groups were 43 years (range 39-48) for the anatomical group and 48.4 (range 36-58) for the non-anatomical group. All the 36 patients treated were male. The dominant extremities were 8 out of 16 in the Group A and 13 out of 20 in the Group B. The mean interval between the injury and the surgery was 9 days (range 4-20) in the anatomical group and 8 days (range 2-21) in the non-anatomical group. All chronic ruptures ( $>21$ days) were excluded from this study. We evaluated the range of motion (ROM) of the injured arms in both groups. The subjective clinical condition of the patients was analyzed using a satisfactory scale (0-100), the DASH score (Disabilities of Arm, Shoulder and Hand), the Oxford elbow score and the MEPS (Mayo Elbow Performance Score).

\section{Surgical techniques}

\section{The anatomical approach}

The patient was positioned supine with the elbow extended and the forearm supinated. An anterior transverse $3 \mathrm{~cm}$ incision was performed in the proximal forearm centered at the elbow crease. The torn tendon end was isolated and debrided. Two Fiberwire n. 2 (Arthrex, Naples, Florida, USA) were used to prepare the tendon with Bunnell-like sutures. The radial tuberosity was visualized under fluoroscopy and two drill holes were created with $1,7 \mathrm{~mm}$ Kirschner wire with a loop.

The $\mathrm{K}$ wires are positioned proximally to distally in order to decrease the length of surgical incision. Moreover, in order to restore as accurately as possible the anatomical insertion and consequently the supination ability, the $\mathrm{k}$ wires inclination is about 30 degrees from medial to lateral.

The proximal hole was centered on the apex of the radial tuberosity and the distal hole at the end of the tuberosity; making sure to drill the two holes almost perpendicular to the bone surface, slightly convergent. The forearm was completely supinated during the drilling, in order to achieve the most medial part of the tuberosity and avoiding the interosseous nerve. The sutures were passed through the two drill holes from the volar to the dorsal side through a shuttling technique using the looped $\mathrm{K}$-wire with the forearm completely supinated. A small incision $(<1 \mathrm{~cm})$ was performed on the dorsal side between the two k-wires extremities and the ruptured tendon was reattached to the tuberosity by pulling the sutures and firmly tying the knot. The tension of the biceps was finally evaluated through the volar incision.

\section{Non-anatomical approach}

The position of the patient was the same of the anatomical approach; the patient was supine with the elbow extended and the forearm supinated. An incision was performed medially and proximally to the elbow fold and it was obliquely extended distally and laterally. The ruptured distal biceps brachii tendon was retrieved. The avulsed biceps tendon was then sutured to the brachialis muscle passing throughout its distal tendon. The elbow was flexed at $30^{\circ}$, in order to restore the adequate biceps muscle tension.

\section{Rehabilitation protocol}

The rehabilitation protocol was the same in both groups. The arm was immobilized in a shoulder sling brace for 15 days following surgery. Thereafter, the patient started with active range of motion without heavy weights. Sport activity was allowed only three months after surgery.

\section{Isokinetic Evaluation}

In our study, we assessed the functional performance using an Isokinetic muscle testing (Biodex System 4 pro, Shirley, NY, USA) to all the 36 patients. We evaluated two types of movements in both arms: flexion/extension and supination/ pronation. All the patients were carefully instructed on isokinetic testing and performed a 5-minuted warm-up before the definitive tests. The healthy arm was tested prior to the injured arm. The patient was placed in a beach-chair position with an upper body exercise table (UBXT) throughout all the tests. The flexion/extension was evaluated with a range of motion between $0^{\circ}$ and $150^{\circ}$. The supination/ pronation was performed with a range of motion between 
$80^{\circ}$ of supination and $80^{\circ}$ of pronation. Both movements, flexion/extension and supination/pronation, were evaluated at two different angular velocities: 90 degree/second (5 repetitions) and 210 degree/second (15 repetitions). We used these results to determine the Peak Torque (PT), Total Work (TW) and Endurance (E). The differences between the dominant and non-dominant arms were considered in our statistical analysis.

\section{Statistical analysis}

Continuous variables were assessed as means, standard deviations and quartiles. The Wilcoxon Two-Sample Test was used to evaluate the differences between the two groups for quantitantive variables, while the Chi-Square or the Fisher's Exact Test were used to evaluate qualitative variables; statistical analyses were carried out at two-sided with a 0.05 significance level, using $\mathrm{SAS}^{\circledR}$ (Version 9.4, SAS Institute Inc., Cary, NC, USA) and STATAtm version 8.2 (Stata Corporation, College Station, Texas, United States).

\section{RESULTS}

The baseline characteristics of the two groups are shown in table I.

No significant differences were detected between the two groups with respect to any of the clinical or patient reported outcome measures assessed except for ROM injured side in flexion. This information is summarized in table II.

The dynamometric tests demonstrated a statistical significant difference in the Peak Torque, evaluated in flexion in the anatomical group compared to the non-anatomical group ( $\mathrm{p}<0.05$ ); this difference was significant both at $90 \%$ seconds and at $210 \%$ seconds. Even though the Total Work and the Endurance evaluated in both groups

Table I. Baseline characteristics.

\begin{tabular}{|c|c|c|c|}
\hline Variable & Group A & Group B & P value \\
\hline Sex $(M ; F)$ & $16 ; 0$ & $20 ; 0$ & $\mathrm{p}>0.05$ \\
\hline Age & $43(39-48)$ & $48.4(36-58)$ & $\mathrm{p}>0.05$ \\
\hline $\begin{array}{l}\text { Dominant side } \\
\text { involvement }\end{array}$ & 8 & 13 & $\mathrm{p}>0.05$ \\
\hline $\begin{array}{l}\text { Mechanism } \\
\text { of injury } \\
\text { (weight } \\
\text { lifting; fall) }\end{array}$ & $16 ; 0$ & $17 ; 3$ & $p>0.05$ \\
\hline $\begin{array}{l}\text { Interval injury- } \\
\text { surgery (days) }\end{array}$ & $9(4-20)$ & $8(2-21)$ & $\mathrm{p}>0.05$ \\
\hline $\begin{array}{l}\text { Follow- } \\
\text { up (months) }\end{array}$ & $27(24-36)$ & $63(40-75)$ & $\mathrm{p}<0.001$ \\
\hline
\end{tabular}

Muscles, Ligaments and Tendons Journal 2021;11 (3)
Table II. Median post-operative clinical outcome.

\begin{tabular}{|c|c|c|c|}
\hline Variable & Group A & Group B & P value \\
\hline $\begin{array}{l}\text { ROM injured } \\
\text { side in flexion }\end{array}$ & $149(145-150)$ & $140(120-150)$ & $\mathrm{p}=0.0005$ \\
\hline $\begin{array}{l}\text { ROM injured } \\
\text { side in } \\
\text { supination }\end{array}$ & $80(80-80)$ & $80(70-87)$ & $\mathrm{p}>0.05$ \\
\hline $\begin{array}{l}\text { Satisfactory } \\
\text { score }(0-100)\end{array}$ & $90(80-100)$ & $85(70-100)$ & $\mathrm{p}>0.05$ \\
\hline DASH score & $\begin{array}{l}3.3 \\
\text { (range 0-11.7) }\end{array}$ & $\begin{array}{l}5.2 \\
\text { (range 0-12.5) }\end{array}$ & $\mathrm{p}>0.05$ \\
\hline $\begin{array}{l}\text { Oxford } \\
\text { elbow score }\end{array}$ & $\begin{array}{l}43 \\
\text { (range 39-48) }\end{array}$ & $\begin{array}{l}41 \\
\text { (range 37-48) }\end{array}$ & $p>0.05$ \\
\hline MEPS & $\begin{array}{l}100 \\
\text { (range 90-100) }\end{array}$ & $\begin{array}{l}100 \\
\text { (range 80-100) }\end{array}$ & $\mathrm{p}>0.05$ \\
\hline
\end{tabular}

during flexion presented higher scores in the anatomical group, these differences were not statistically significant (figure 1).

Moreover, the PT, TW and E evaluated in both groups during supination demonstrated higher values in the anatomical groups respect to the non-anatomical group (figure 2), although these results were not statistically significant.

Furthermore, we evaluated the differences between the dominant arms in the two groups and the differences between the dominant and the non-dominant extremities in each group. The values obtained with the dominant limbs in the anatomical group demonstrated an overall superiority than those obtained

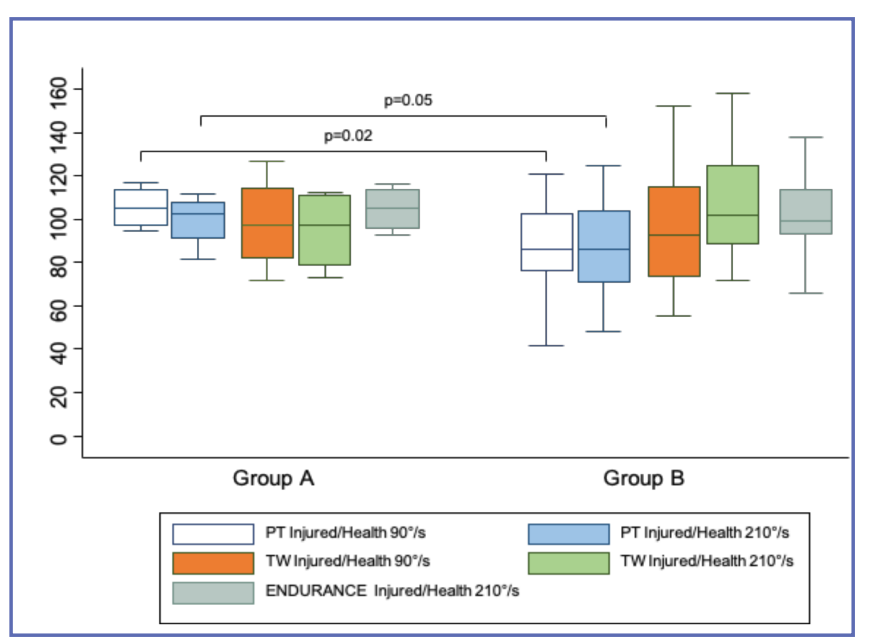

Figure 1. Group A vs Group B in Flexion: demonstrating a statistical significant difference in the Peak Torque both at $90 \%$ and $210 \%$ s. 


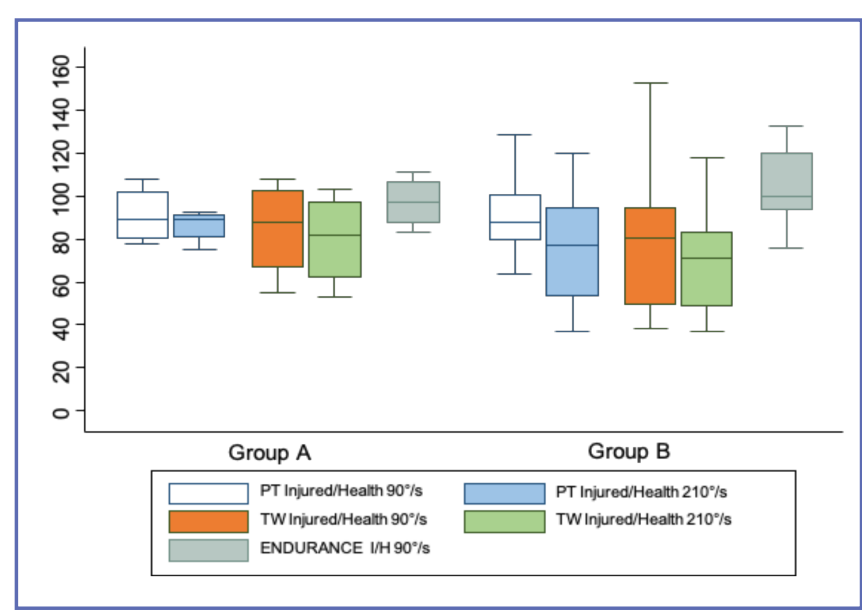

Figure 2. Group A vs Group B in Supination: presenting higher values in the Group A, even though this difference is not statistically significant.

with the dominant extremities in the non-anatomical group during both flexion and supination as showed in figure 3 .

The statistical significant results achieved with the dominant arm rather than the non-dominant in the anatomical group in all movements were emphasized in figures $\mathbf{4}$ and $\mathbf{5}$.

No major complications in any of the patients were reported. In the non-anatomical group transient paresthesia of the anterior cubital area was reported in two patients, no other minor complications were reported.

\section{DISCUSSION}

Different studies recommended the surgical compared to the non-operative treatment to manage distal biceps tendon

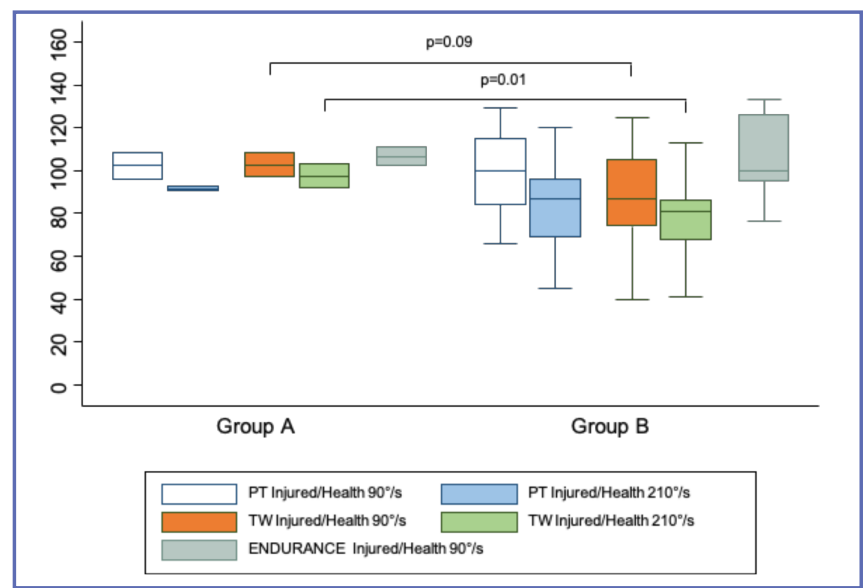

Figure 3. Group A vs Group B: Dominant Arm in Supination. A statistical significant difference was reported in the Total Work between the dominant arms of the two groups during supination.

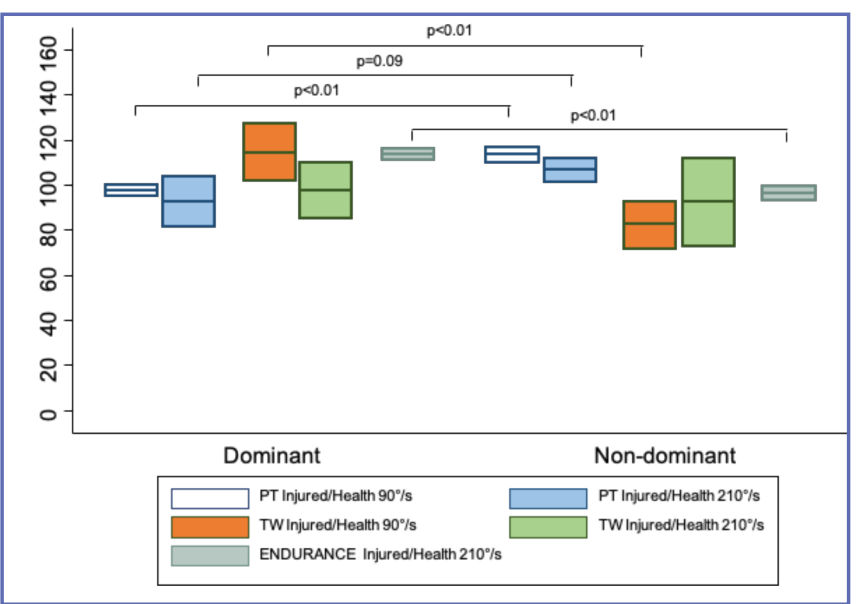

Figure 4. Group A: Dominant vs Non-Dominant in Flexion. In the Group A evaluated in flexion, the dominant arms obtained an overall superiority compared to the non-dominant arms, with a statistical significant difference in all the dynamometric tests (except the TW at $210^{\circ} / \mathrm{s}$ ).

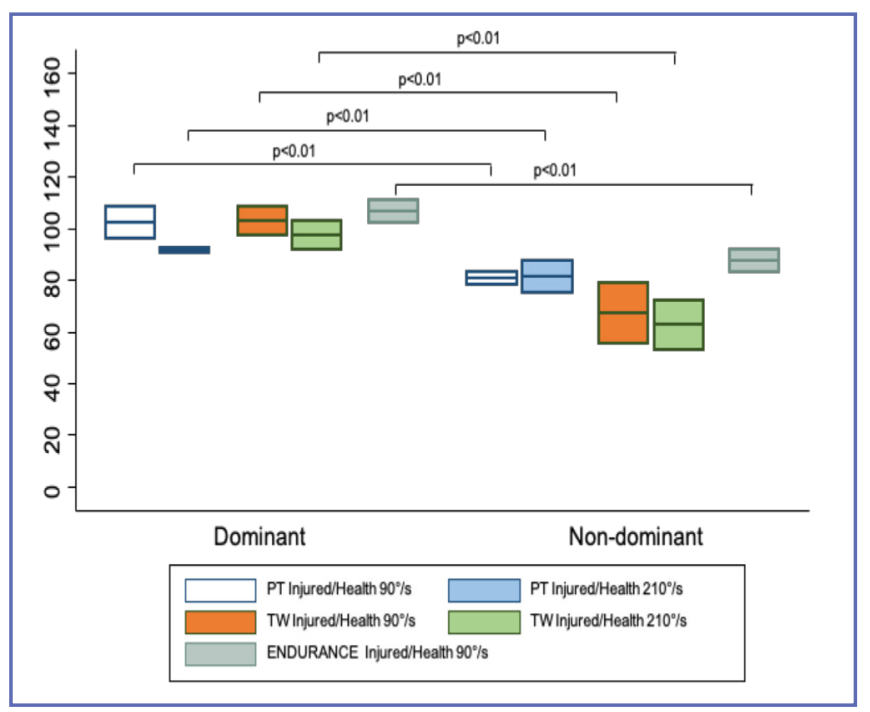

Figure 5. Group A: Dominant vs Non-Dominant in Supination. In the Group A evaluated in supination, the dominant arms obtained a statistical significant difference in all the dynamometric tests performed.

ruptures $(6,7)$. Nowadays, conservative option is usually recommended only in elderly patients with low-demand activities or with important comorbidities (5).

Even though the surgical treatment is now considered the treatment of choice, there is not a general agreement on which is the best surgical approach. 
Some authors prefer the single anterior approach (16-18); while others prefer the Boyd and Anderson double-incision technique $(1,10,11,19)$. Even though the two-incision technique limits the volar surgical dissection, it has been associated with important complications including proximal radio-ulnar synostosis (20), formation of proximal radio-ulnar calcifications and lesions on the posterior interosseous nerve (21). Moreover, the double-incision technique has been associated, in a longterm follow-up, to a decrease in the range of motion of more than $30 \%$ in supination/pronation, a decrease in supination strength and a decrease of total work (TW) in supination (22). The reinsertion of the avulsed distal biceps tendon can be performed either anatomically or non-anatomically. The anatomical surgery involves the reattachment of the distal tendon of the biceps in the anatomical footprint on the radial tuberosity, hypothetically maintaining the biomechanical advantage of the native tendon. Whereas, the non-anatomical surgery consists in the tenodesis of the ruptured distal biceps on the anterior brachialis muscle tendon, altering the native biomechanics of the forearm. Through the years the non-anatomical approach has been gradually abandoned, although satisfactory results obtained using this technique were reported $(8,23)$.

Different fixation devices can assist in the anatomical reinsertion: suture anchors (24), interference screws (16) or suspension devices (25). Some others searching for the maximal biomechanical stability combined more devices in a single procedure (14). Unfortunately, major complications have been reported with the use of these fixation devices: suture anchors have been associated with posterior interosseous nerve lesions (24), suture breakage (26), slippage of the anchor (26) and proximal radial fracture (27); fatigue fractures have been reported with the insertion of interference screws (26); posterior interosseous nerve palsies (28), superior branch of radial nerve injuries (28), heterotopic ossifications (25) and disengagement (28) have been reported with the use of cortical button. The anatomical technique used in our study, even though could be considered less stiff than the anatomical procedures using fixation devices, allow us to avoid possible major complications still maintaining a strong initial fixation (10).

In our study the isokinetic tests results obtained using either the non-anatomical surgery with the biceps tenodesis on the brachialis tendon or the anatomical single-incision transosseous tunnels approach, were both satisfactory.

The PT, the TW and E registered during flexion/extension and supination/pronation reported higher values in the anatomical group compared to the non-anatomical group, emphasizing the objective superiority of the former group. However, it is important to highlight that not all the results presented a statistical significant difference between the two groups.
In our study the dominant extremities demonstrated higher improvement compared to the non-dominant limbs in both groups. We correlated this phenomenon with a potential more vigorous physical therapy or daily work-related exercises performed in the dominant compared to the non-dominant limbs or to the difference in strength normally present between the dominant and the non-dominant arms.

All the patients were treated acutely $(<21$ days $)$ in our study; the mean interval from the injury to the surgery was 8-9 days in both groups. We managed to diagnose all the injuries in the Emergency Room of our Hospital and surgically repair the lesions as soon as possible, avoiding the possible complications related to the chronic ruptures of the distal biceps (29).

In our opinion, the results obtained in our two groups of patients were both satisfactory, in terms of functional recovery and range of motion, as demonstrated objectively by the isokinetic tests. Our tests however, confirmed our null hypothesis, emphasizing the superiority of the anatomical surgery compared to the non-anatomical approach in all the tests performed, with a greater improvement in terms of supination strength but not always statistically significant.

Moreover, the anatomical approach performed in our study is a minimally invasive procedure, cost-effective, timesaving and without the use of rigid fixation devices associated with all the complications aforementioned.

Our results suggested that even though the anatomical approach should be considered the treatment of choice to repair distal biceps tendon avulsions, the non-anatomical approach was able to achieve satisfactory clinical and functional results.

The major limitation of our study was the follow-up: different follow-ups between the two groups with a shorter follow up in the anatomical group. This difference is related to the increasing percentage of patients anatomically treated during the last years. This bias might play an important role in the isokinetic evaluation, allowing the non-anatomical group a longer adaptation period to compensate the residual functional deficits. Another limitation involved the small sample of patients involved in the study.

\section{CONCLUSIONS}

The anatomical technique using transosseous tunnels is an easy, safe and effective procedure when utilized in patients with acute distal biceps brachii ruptures with a low risk of surgical complications. Although the non-anatomical treatment presented satisfactory results, the anatomical treatment is able to significantly reduce all the residual functional deficits usually present after the repair. The dominant arm achieved superior outcomes in all movements compared to non-dominant arm. 


\section{ETHICS}

Institutional review board approval from La Sapienza University of Rome was granted for the study (132/2019). The study meets the ethical standards of the journal (30).

\section{CONFLICT OF INTERESTS}

The authors declare that they have no conflict of interests.

\section{REFERENCES}

1. D'Alessandro DF, Shields CL, Tibone JE, Chandler RW. Repair of distal biceps tendon ruptures in athletes. Am J Sports Med 1993;21(1):114-9.

2. Ramsey ML. Distal biceps tendon injuries: diagnosis and management. J Am Acad Orthop Surg 1999;7(3):199-207.

3. Safran MR, Graham SM. Distal Biceps Tendon Ruptures: Incidence, Demographics, and the Effect of Smoking. Clin Orthop Relat Res 2002;404:275-83.

4. Leighton MM, Bush-Joseph CA, Bach BR. Distal biceps brachii repair. Results in dominant and nondominant extremities. Clin Orthop 1995;(317):114-21.

5. Krumm D, Lasater P, Dumont G, Menge TJ. Brachial distal biceps injuries. Phys Sportsmed 2019;47(4):406-10.

6. Baker BE, Bierwagen D. Rupture of the distal tendon of the biceps brachii. Operative versus non-operative treatment. J Bone Joint Surg Am 1985;67(3):414-7.

7. Schmidt CC, Styron JF, Lin EA, Brown BT. Distal Biceps Tendon Anatomic Repair. JBJS Essent Surg Tech 2017;7(4):e32.

8. De Carli A, Zanzotto E, Vadalà AP, Luzon D, Di Salvo M, Ferretti A. Surgical repair of the distal biceps brachii tendon: clinical and isokinetic long-term follow-up. Knee Surg Sports Traumatol Arthrosc Off J ESSKA 2009;17(7):850-6.

9. Citak M, Backhaus M, Seybold D. Surgical Repair of the Distal Biceps Brachii Tendon: A Comparative Study of Three Surgical Fixation Techniques. Knee Surg Sports Traumatol Arthrosc Off J ESSKA 2011;19(11):1936-41.

10. El-Hawary R, Macdermid JC, Faber KJ, Patterson SD, King GJW. Distal biceps tendon repair: comparison of surgical techniques. J Hand Surg. 2003 May;28(3):496-502.

11. Boyd HB, Anderson LD. A Method for Reinsertion of the Distal Biceps Brachii Tendon. JBJS 1961;43(7):1041-3.

12. Bellringer SF, Phadnis J, Human T, Redmond CL, Bain GI. Biomechanical comparison of transosseous cortical button and Footprint repair techniques for acute distal biceps tendon ruptures. Shoulder Elb 2020;12(1):54-62.

13. van den Bekerom MPJ, Kodde IF, Aster A, Bleys RLAW, Eygendaal D. Clinical relevance of distal biceps insertional and footprint anatomy. Knee Surg Sports Traumatol Arthrosc Off J ESSKA 2016;24(7):2300-7.

14. Watson JN, Moretti VM, Schwindel L, Hutchinson MR. Repair techniques for acute distal biceps tendon ruptures: a systematic review. J Bone Joint Surg Am 2014;96(24):2086-90.
15. Schmidt CC, Weir DM, Wong AS, Howard M, Miller MC. The effect of biceps reattachment site. J Shoulder Elbow Surg 2010;19(8):1157-65.

16. Krushinski EM, Brown JA, Murthi AM. Distal biceps tendon rupture: biomechanical analysis of repair strength of the Bio-Tenodesis screw versus suture anchors. J Shoulder Elbow Surg 2007;16(2):218-23.

17. Pereira DS, Kvitne RS, Liang M, Giacobetti FB, Ebramzadeh E. Surgical repair of distal biceps tendon ruptures: a biomechanical comparison of two techniques. Am J Sports Med 2002;30(3):432-6.

18. Sotereanos DG, Pierce TD, Varitimidis SE. A simplified method for repair of distal biceps tendon ruptures. J Shoulder Elbow Surg 2000;9(3):227-33.

19. Tarallo L, Lombardi M, Zambianchi F, Giorgini A, Catani F. Distal biceps tendon rupture: advantages and drawbacks of the anatomical reinsertion with a modified double incision approach. BMC Musculoskelet Disord 2018;19(1):364.

20. Ford SE, Andersen JS, Macknet DM, Connor PM, Loeffler BJ, Gaston RG. Major complications after distal biceps tendon repairs: retrospective cohort analysis of 970 cases. J Shoulder Elbow Surg 2018;27(10):1898-906.

21. Dunphy TR, Hudson J, Batech M, Acevedo DC, Mirzayan R. Surgical Treatment of Distal Biceps Tendon Ruptures: An Analysis of Complications in 784 Surgical Repairs. Am J Sports Med 2017;45(13):3020-9.

22. Davison BL, Engber WD, Tigert LJ. Long term evaluation of repaired distal biceps brachii tendon ruptures. Clin Orthop 1996;(333):186-91.

23. Klonz A, Loitz D, Wöhler P, Reilmann H. Rupture of the distal biceps brachii tendon: isokinetic power analysis and complications after anatomic reinsertion compared with fixation to the brachialis muscle. J Shoulder Elbow Surg 2003;12(6):607-11.

24. Burton KJ, Arciero R. Distal biceps brachii tendon repair: Suture anchor technique. Oper Tech Sports Med 2003;11(1):47-50.

25. Greenberg JA, Fernandez JJ, Wang T, Turner C. EndoButton-assisted repair of distal biceps tendon ruptures. J Shoulder Elbow Surg 2003;12(5):484-90.

26. Mazzocca AD, Burton KJ, Romeo AA, Santangelo S, Adams DA, Arciero RA. Biomechanical Evaluation of 4 Techniques of Distal Biceps Brachii Tendon Repair: Am J Sports Med 2017;35(2):252-8.

27. Badia A, Sambandam SN, Khanchandani P. Proximal radial fracture after revision of distal biceps tendon repair: a case report. J Shoulder Elbow Surg 2007;16(2):e4-6.

28. Kodde IF, van den Bekerom MPJ, Eygendaal D. Reconstruction of distal biceps tendon ruptures with a cortical button. Knee Surg Sports Traumatol Arthrosc Off J ESSKA 2015;23(3):919-25.

29. Kelly EW, Morrey BF, O’Driscoll SW. Complications of repair of the distal biceps tendon with the modified two-incision technique. J Bone Joint Surg Am 2000;82(11):1575-81.

30. Padulo J, Oliva F, Frizziero A, Maffulli N. Muscles, Ligaments and Tendons Journal - Basic principles and recommendations in clinical and field Science Research: 2018 update. Muscles Ligaments Tendons J 2018;8(3):305-7. 